\title{
AN INFORMATION TECHNOLOGY TOOL TO SUPPORT NEGOTIATING TEAMS
}

\author{
José A. Pino* and José M. Montañana \\ Depto. de Ciencias de la Computación, Universidad de Chile \\ Casilla 2777 \\ Santiago, Chile \\ E-mail:jpino@dcc.uchile.CL
}

\begin{abstract}
This paper discusses computer-supported large-scale negotiation, in particular, negotiation with advisers. It is claimed that better communication within negotiating teams should lead to longer, more productive sessions than the current ones. To this end, an information technology environment should be provided for the negotiation. The paper introduces SHINE, a collaborative software system developed at the University of Chile. This software has many features to allow rich interactions among advisers belonging to the same team, among negotiators and also between a negotiator and his advisers. Emphasis is placed on the design features to enable and ease these interactions. The facilities include WYSIWIS windows, enhanced electronic mail to send and receive text or video messages with several urgency levels, an evaluation procedure and various ways to state comments and ideas. SHINE has been implemented as a prototype on Sun Sparc workstations.
\end{abstract}

\section{INTRODUCTION}

This paper deals with designing a computer-based system to support negotiations among teams of people. Such system should enable users to accomplish their task in a more efficient way than without it. The system is not intended to model the negotiation or try to optimize the outcomes in a game-theory approach, but rather to improve the communication among participants.

It is important to note that communication during a negotiation is needed not only among negotiating teams, but within the teams themselves. The objective of the system to be described below is to enable such communication while the negotiation is in progress. This would make the negotiation more efficient because the members of each team would be in

\footnotetext{
* This work has been partially supported by Fondo Nacional de Investigación Científica y Tecnologica (FONDECYT), project No. 92-1162, and a grant from Synapsis S.A.
} 
permanent, close and private communication among themselves as well as being talking with the other parties in a face-to-face setting.

This computer-based system can be considered a Computer-Supported Collaborative Work (CSCW) development. According to Ellis et al. (1991), CSCW reflects a change in emphasis from using the computer to solve problems to using the computer to facilitate human interaction. Challenging issues in the design of good CSCW systems are the coordination among members (Malone and Crowston (1990)), effective collaboration devices and humancomputer interfaces (Ellis et al. (1991)).

Collaborative systems have been applied to brainstorming (Stefik et al. (1987)), document writing (Fish et al., (1988); Pino and Fabres (1993)), drawing (Bly and Minneman (1990)), group decision making (Nunamaker et al. (1991)), spreadsheet use (Fuller et al. (1993)), folder circulation (Karbe et al. (1990)) and software development (Hahn et al. (1991)). Among their advantages over stand-alone systems, include freer participation, increased productivity, and in the case of remote systems, no burden of personal transportation to a meeting site.

\section{NEGOTIATION WITH ADVISERS}

According to sociologist Julien Freund, conflicts among groups of people arise because they become hostile over maintaining, reaffirming or restoring their rights (Freund (1983)). From the point of view of one of the groups, it is necessary to break the resistance of the members of the other groups. The Latin word hostis and the Greek word polemios describe this type of rival or enemy, rather than inimicus (Latin) or ejzróz (Greek), which characterize a private opponent (Schmitt (1985)).

Social conflicts may arise because different groups hold opposed economic, political, national or religious views. For example, an economic conflict occurs when the organized workers of a certain sector ask for salary increases the organized managers consider excessive. An example of a political/international conflict may arise because two Governments claim sovereignity over a certain geographical region for their respective countries. In both cases, there may be mediators (e.g., the Ministry of Labor in the former and the United Nations in the latter).

A conflict of this kind may be settled by force. Alternatively, there may be negotiation, that is, each party agrees to talk in order to accept part of the others' point of view if its own claims are partly accepted as well.

A typical negotiation setup is composed of two or more parties (eventually one of them may be a mediator). In the technical literature, there is a distinction between the terms "negotiation" and "bargaining" although in everyday English usage they are considered synonyms. Negotiation involves human interactions defying quantitative analysis whereas bargaining refers to situations that can be modeled and analyzed (Nierenberg (1973)). Both terms are not necessarily disjunct, because a bargaining model can be used within a negotiation (Fraser and Hipel (1984)). As an example, Fraser and Hipel describe the Holston River negotiations which occurred in the early 70's in the state of Tennessee (U.S.A.); they 
apply conflict analysis to develop a bargaining model which could have been used in these negotiations.

According to Bacharach and Lawler (1981), power is the essence of negotiation, and the negotiating power is subjective power. This means that it is important for a party to convey the impression of controlling significant exchange commodities. In particular, a way to alter the opponent's definition of the power situation is to manipulate information, argument, do bluffing, etc. Therefore, each party is best represented by a group head or negotiator and several assistants or advisers. The speaker of each group is the negotiator. The assistants, given their specialization in various fields, provide a negotiator with the necessary expert information to apply good negotiating power tactics. Thus, for an international peace talk, for instance, assistants may be experts in subjects such as international law, geography, military affairs, national politics, etc. Typically, assistants are seated behind their negotiator. In the Holston River example, there were three major participants, each party having consultants and advisers.

During a negotiation session, an individual assistant may approach his negotiator and deliver a short verbal comment or quickly pass him a written note. In many cases, that is all the information the negotiator gets from his group during the talk. A negotiator may request a break or a new meeting in order to have enough time to discuss new proposals with his advisers. Therefore, the negotiator-assistants interaction during a meeting is poor, and the negotiator may get worried of saying too much because he does not have enough input from the experts of his side. As a consequence, interruptions slow down the negotiation. On the other hand, if a negotiator does indeed give away what it is more than convenient to the other party due to lack of counsel, later on he may be unwilling to give any other concession and this may result in stalling progress in other aspects of the negotiation.

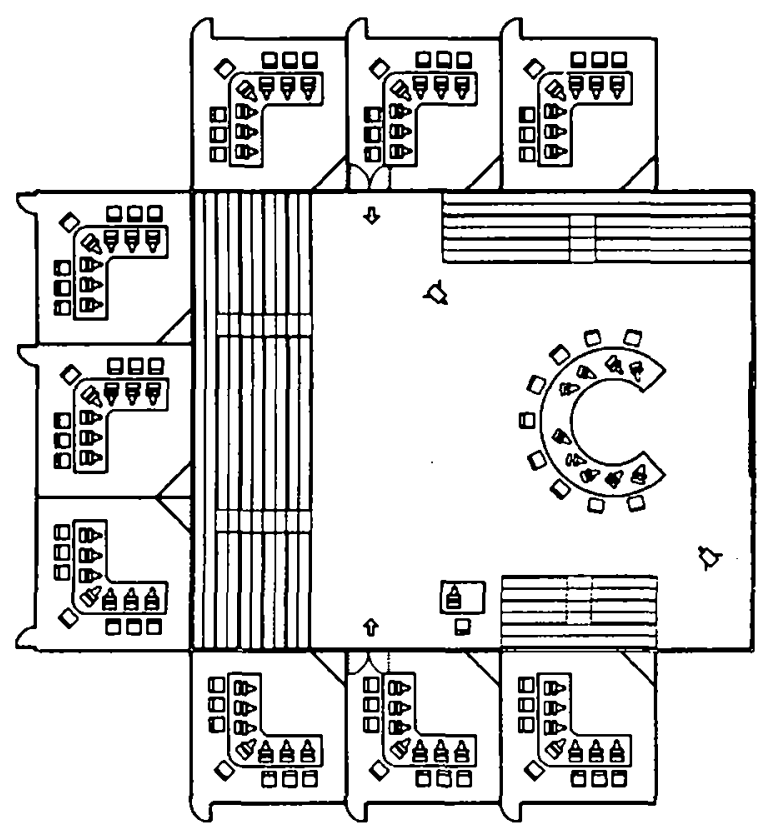

(a)

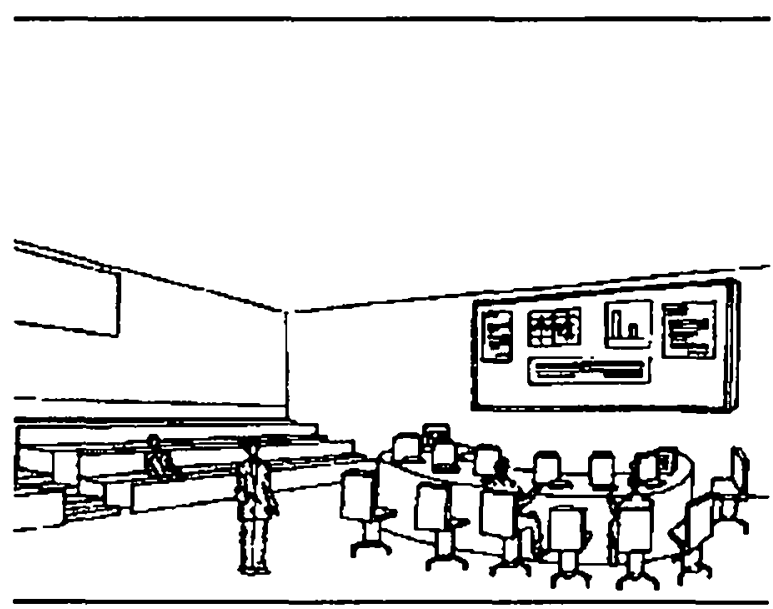

(b)

Figure 1. Negotiating room and nine advisers' rooms. (a) The electronic board is on the right wall of the negotiating room; the shaded area represents seats for journalists and public. The diagonal line in each advisers' room represents the TV monitor. (b) This view of the negotiating room shows the board and part of an advisers' room window. 
An improvement over the previous situation is to furnish a voice communication system linking negotiators and their assistants. This system would complement the traditional voice communication system designed to listen the current speaker, in more than one language if translators are provided. However, if multiple communication channels were available, we could have a better comprehension, since it is well-known that the use of several channels eases the communication among people (Bettinghaus (1980)). In this case, the communication channels might be voice, written text, visual icons and video. A computerbased multimedia system could provide these channels and an appropriate software might allow the negotiator to continue listening to the current speaker while asking counsel with a few hand movements over a computer mouse, or quickly see the first opinions of his experts on a recent proposal presented by the opposing party. The negotiator would have the option of interacting with his workstation whenever he thinks that the complexity of the current speech is low enough to do so. Thus, the negotiator-assistants interaction could become intense and efficient.

An additional shortcoming of the traditional approach to negotiation is that the advisers do not enjoy privacy or isolation to exchange views during the meeting. As a result, the input they can provide to the negotiator is only based on personal opinions.

These considerations led to the design of SHINE (Shared Interactive Negotiation Environment). This software system was developed as part of a larger project aimed at investigating the potential of adequate human-computer interfaces to build useful collaborative systems.

\section{DESIGN OF THE ENVIRONMENT}

Our proposal calls for a redesign of the physical negotiating environment (Fig. 1). A separate room is provided for each group of assistants. This room has a window to the negotiating room and a video monitor to receive the audio and close-ups from the speaking negotiators. Each assistant is provided with a workstation and a video camera focusing on him.

The negotiators remain on the main floor, each with a workstation in front. Workstation screens are only visible by their corresponding negotiators. There is a large electronic board, controlled from a terminal by a technician.

A negotiator may speak as usual, but he may also send short text messages to designated negotiators by typing on his workstation and send text, pictures or tables to the technician to be displayed on the electronic board. He may also have a contents-rich communication with his assistants.

Up to seven advisers engage in a permanent face-to-face meeting in their room and they communicate through their workstations among themselves and with their negotiator. They can have private or shared views over text documents and send tables or pictures to each other. The idea of the assistants' reduced participation in the meeting was inspired by an early experience in group dialog reported by Sheridan (1971). To have a group of interconnected computer-supported people do a joint task requiring discussion in a face-to-face meeting seems to be a successful arrangement, as reported by Nunamaker et al. $(1989 ; 1991)$ in the case of the group decision-making area. 
A method to move a stalled negotiation is to generate new ideas in a brainstorming process (Fisher and Ury (1981)). This can easily be done by the advisers in the privacy of their room, according to this design. A negotiator should be able to ask some or all advisers to have a small brainstorming session about a specific subject while the negotiation is in process.

The advisers may send the negotiator written proposals, short telegrams of high priority and evaluations of various kinds previously asked by the negotiator. They may also send a video message consisting of a recording of one of the advisers speaking. The latter type of message has the advantage of letting the negotiator watch the facial emphasis the assistant wants to provide. However, it has the disadvantage the negotiator has to switch audio channels and perhaps miss another negotiator's speech.

\section{INTERFACE DESIGN}

The human-computer interface of SHINE was carefully designed considering that first, the users are supposed to be computer novices, and second, the negotiator can not afford much time to interact with his workstation. Thus, the user interface is icon-based.

The negotiator communicates with two basic paradigms displayed on his screen: a pushbutton panel and a bulletin board. The panel is very simple to manipulate: the user chooses an icon, presses a mouse button and the action occurs. For example, if an icon signals that mail messages have arrived, choosing it causes a window to be opened showing the contents of the messages. The bulletin board is of simple operation as well and it is explained in the next section.

Display of results is also visual. For example, evaluation results are shown using faces, with obvious meanings: smiling, annoyed, etc.

Figure 2 shows the negotiator's workstation screen. The control panel is a private window shown on the left hand side. In its upper part, there are icons depicting the assistants; the first one represents the whole group of advisers. These icons are useful to selectively ask the services explained below. An arbitrary number of advisers can be chosen for a service by pointing with the cursor over each icon in turn and depressing the first mouse button (selection is indicated by an icon shade change). A second button depression deselects the corresponding icon. People icons are also useful to show their current state and keep the negotiator informed. In Fig. 2, Adriana is out of the room while Alejandra is in the assistants' room but she is busy with another task.

Besides a bulletin board and a control panel, an adviser screen includes a strict WYSIWIS window (Stefik et al. (1987)) called Ours. This window allows advisers to have a place to propose tentative writings, exchange comments, etc. The system automatically inserts a cursor with the author's name whenever an adviser begins to write in this window. Once the writing is finished, the author's name remains as a signature in the last place occupied by the cursor. 


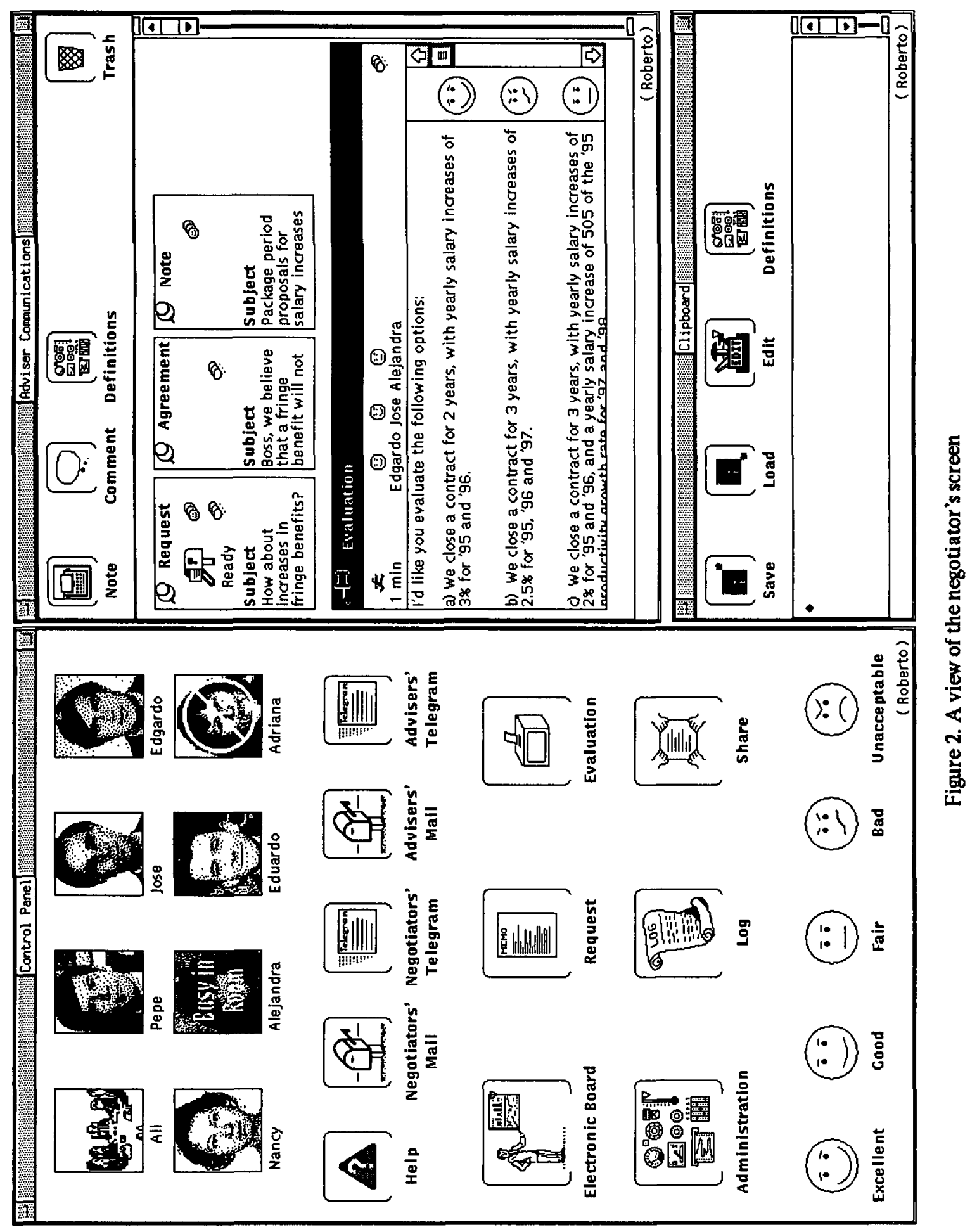




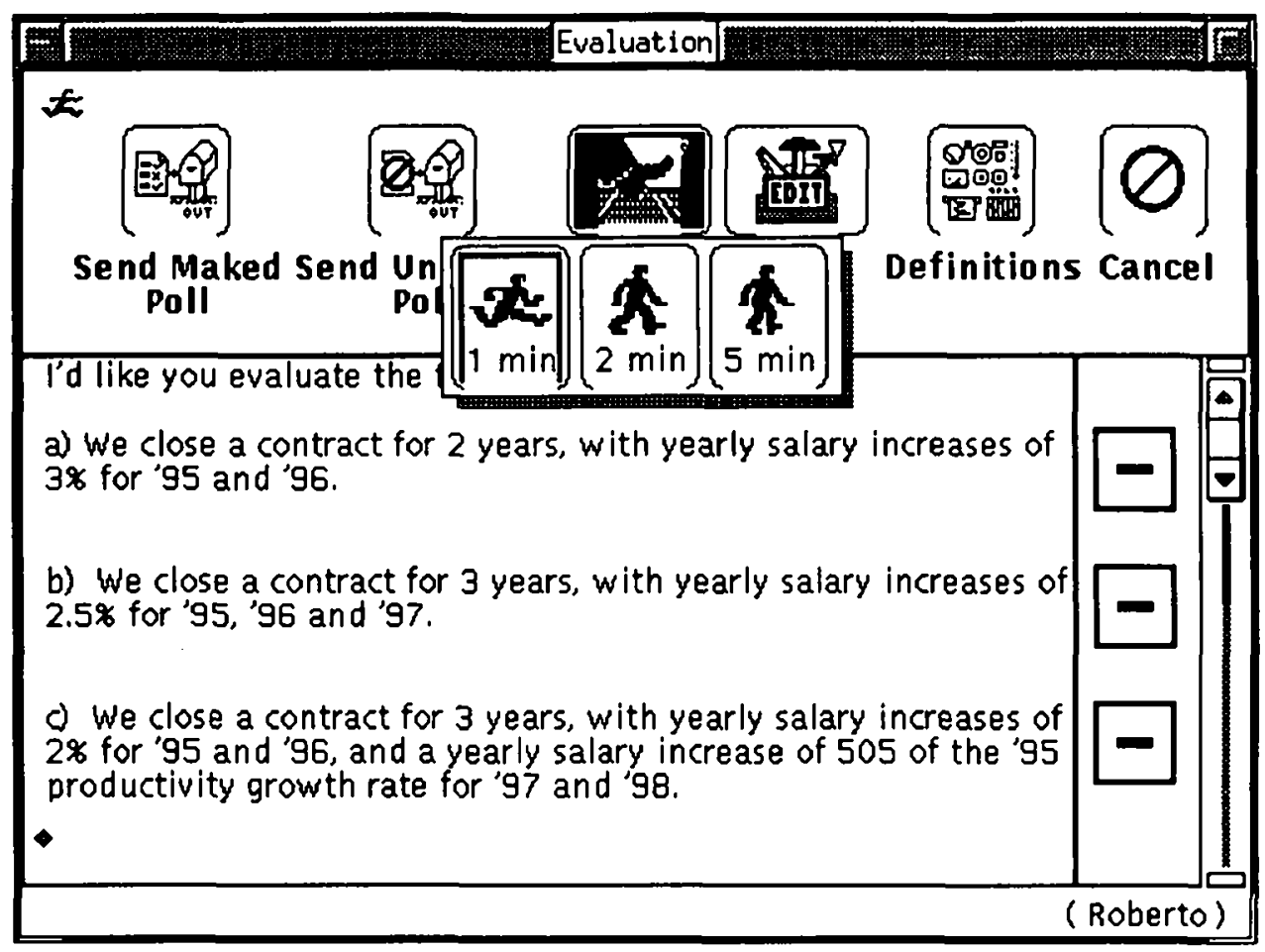

Figure 3. Dialog box at the negotiator's screen used to ask for an evaluation.

\section{THE BULLETIN BOARD}

The bulletin board is a non-strict WYSIWIS window shared with the advisers. There are pinned down items on this board which can be opened by the negotiator or any adviser. If one person opens an item by selecting its pin, another window pops up only on his screen showing the contents of the item; selecting that pin again closes the window and a "closed" item icon appears on the board. Figure 2 shows three closed items: a request, an agreement and a note, and one open evaluation. The closed request is ready.

The open evaluation of Fig. 2 illustrates the type of service the negotiator may need from his advisers. The assistants are asked to vote on one or more texts. When the negotiator presses the evaluation button on the control panel, a dialog box appears (shown on Figure 3) and he writes the texts on which he wants feedback, chooses the urgency of the matter (explained in the next chapter), selects the advisers and then presses the Send Maked Poll button on the dialog box. Thereafter, the box disappears. The "Maked Poll" is the way of doing this service in which the negotiator formats the options himself.

The dialog box has a vertical line separating two columns: the left one to contain text and the right one to place urns. Urns are placed in front of the text to be evaluated, simply by depressing the mouse button when the cursor is in the right place: the system automatically inserts an urn; in fact, in order to further help the user, the cursor changes shape to a shaded urn when the cursor is in the right column.

An alternative way of doing the evaluation is to ask one of the advisers to prepare the questions for his colleagues. In this case, the negotiator simply writes an outline of the options to be evaluated and presses the Send Unmaked Poll button before choosing the helping assistant. 
Once a maked evaluation reaches the chosen advisers, a window appears on their workstation screens. Perhaps they exchange views briefly and then each one casts his votes. The vote format is very simple: only five choices are available and range from excellent to unacceptable. An adviser simply selects a "face" representing his choice and drags it to the urn at the side of the text being evaluated. When finished, each adviser presses a send button. At any time during this process, a team member can open the evaluation item and see the votes already cast. The open evaluation in Fig. 2 shows such results: the faces at the right hand side represent the vote average each option received; clicking on one face shows the individual votes for the corresponding option.

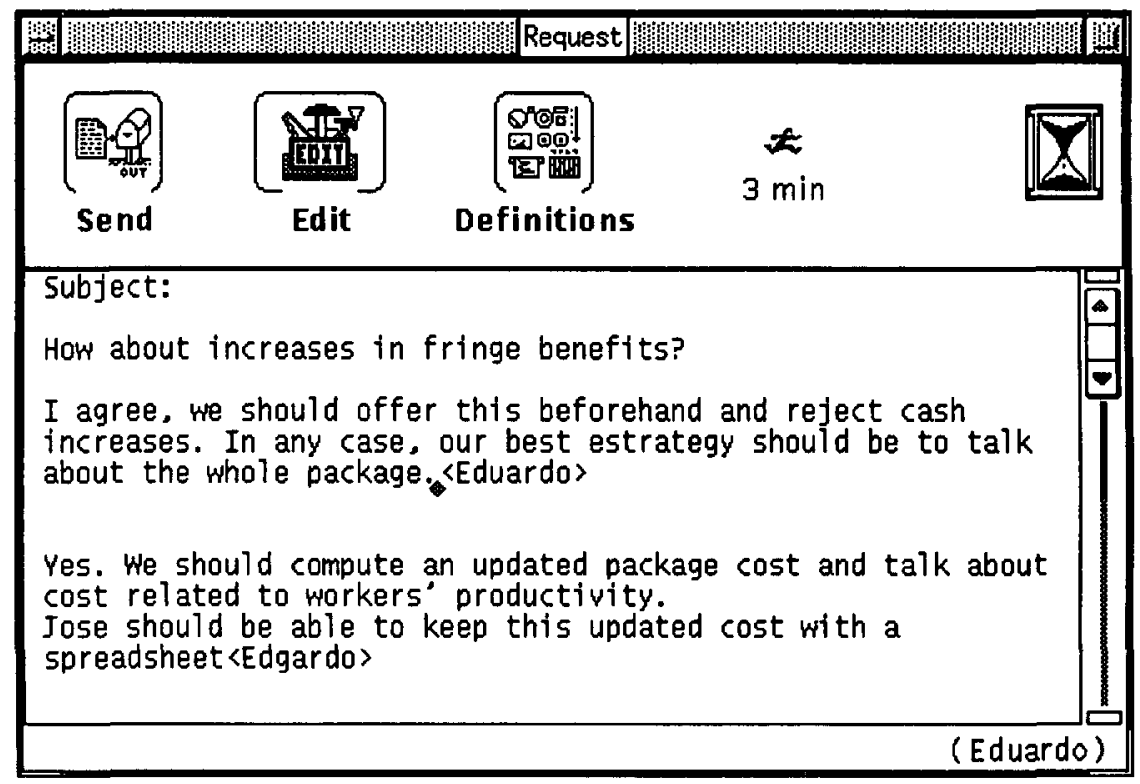

Figure 4. WYSIWIS window provided to the assistants working on a request.

Another service available for the negotiator is the request. It is a petition to one or more advisers to work on a subject and provide an opinion or position. This feature allows the negotiator to ask his advisers to begin a brainstorming session to generate optional solutions to a particular issue. The system provides a WYSIWIS window - similar to the "Ours" window - to the selected assistant (shown on Figure 4). When they are finished writing, one of them presses a send button. Since it is a shared service, the system asks for confirmation, and once received, the shared window is gone and a "ready" signal appears in the respective closed item of all bulletin boards of the negotiating group.

\section{COMMUNICATION USING SHINE}

Important features of communication in the context of negotiation are the specification of task urgency by the sender and the perception of this specification by the recipient of the corresponding message. In requests and evaluations, the negotiator specifies one out of three urgency levels when completing the dialog box. The three levels of urgency have pre-assigned suggested completion times, and when the task related window appears at the advisers' workstations, a sand clock in the upper part of the window depicts the remaining time to complete the task. Therefore, it is easy for the negotiator to choose an icon illustrating the very urgent concept to ask the assistants maximum priority to get a task done quickly, as it is 
the case of the open request in Fig. 4 which was a very urgent task with a expected reply time of three minutes.

Private communication is done with mail and telegram messages. The difference between them is again, the urgency the sender assigns to them. These messages can be sent from the negotiator to the advisers and viceversa and among negotiators. In the case of negotiators, separate icon buttons are provided for mail and telegram messages from/to negotiators and advisers, in order to avoid confusions (Figure 2). These four buttons are reduced to two team mail and telegram - in the case of advisers, since they are not permitted to communicate with other negotiating teams. The operation of mail and telegram messages is similar; they will be referred as messages in what follows. The receiver selection and message sending has a similar procedure to the one needed for sending a request.

If a negotiator chooses to send a message to another negotiator, SHINE automatically opens another window with the pictures of the negotiators and selection is enabled. This window is also automatically closed when the operation is finished.

Reception of a message is signaled by a mark at the corresponding icon in the control panel. Alternatively, each workstation can be configured using the Definitions button of the telegram or mail window to display messages as soon as they arrive. Immediate display of telegram messages is recommended in the case of the advisers' screens in order not to miss any urgent message from the negotiator. Definitions buttons are provided in all other types of SHINE windows to accommodate various preferences or situations.

To read or write messages, a user simply chooses the mail or telegram icon button on the control panel. A window is open displaying the first unread message. Next and Previous buttons on the window provide the controls to read other messages.

Another button labelled Cancel lets the user close the window. Three other buttons - Write, Edit and Send - require further explanation.

The Write option of the message window clears the text part of the window and enables the user to type a message. Edit provides several services to easily prepare the message. Edit has a menu with options to Paste a text from a buffer, which has previously been Copyed from another text, Include the contents of a file and Read from Clipboard. The Clipboard is a private window, and the text transferred to the message window can be all the contents of the clipboard or only a part of it, as chosen with the Definitions button of the Clipboard window.

Other options of the Edit menu enable the user to Delete a part of the text been written. Undo, of course, reverses the last action. Other Edit options are useful also when reading messages: Write to clipboard, Save to file, Copy to buffer. The Edit environment is also provided in the Evaluation, Request, Agreement and Share windows (the last two are described below). Edit services are also provided with the function keys on the left keypad of the keyboard in the OpenWindows implementation for compatibility with other applications running on this environment.

Once a message is prepared, it can be sent using the Send button. Again, the activity can be customized with the Definitions button. For instance, it can be specified that the system asks confirmation before sending a message. 
An adviser message may also be a video recording. His window has an additional button called video ; when chosen, a familiar VCR control panel is drawn on the window: record, play, pause, rewind and advance forward have the obvious meanings. The negotiator gets the control panel and a time duration indication when reading the message (the record button is disabled); selecting the play button creates a window where the video is shown.

SHINE also provides a tool to support face-to-face discussion and brainstorming. The Share button in the control panel opens a shared window for people in the same room: negotiators or advisers. After choosing the Share button, the user chooses the people with whom the sharing is to occur (it may be all). The shared information is saved when the person who initiated the window selects the Unshare button in the window. Previous Share windows can be viewed again, saved in private files, and deleted using the Read button of the window.

Negotiators also have a tool to improve their presentation of ideas: the electronic board. This device is an additional visual channel which may be used to present complex material in a redundant way (Bettinghaus (1980)). A negotiator wishing to place text or a drawing in the electronic board simply selects this item to be displayed and sends it to a technician. The technician appropriately distributes the various displayed items on the board.

The negotiators can remotely point to a place in the electronic board using a telepointer (Stefik et al. (1987)). Another related service is the extraction of a piece of text being currently displayed. To access these features, the user must select the Electronic Board button of the control panel; a menu offering the Magnifier and Marker choices pops up. The marker activates the telepointer, with the negotiator's name; its movement is controlled by the negotiator's mouse and it is cancelled off by pressing the mouse select button. The magnifier option opens a window on the negotiator's screen showing an outline of the electronic board; the cursor shape is now a magnifier. The mouse select button, in this case, opens another window showing a part of the board pointed by the magnifier cursor. This latter window has normal font size letters and vertical and horizontal scrolling bars; it has edit and cancel buttons with the usual meaning.

\section{FURTHER BULLETIN BOARD ITEMS}

Figure 2 shows another type of item pinned down on the bulletin board: an agreement. This is a presentation made by the assistants to the negotiator. It may be a suggestion or a general proposal made by all the assistants. To write it, one assistant chooses the Agreement button from his control panel and writes it similarly to a message.

The negotiator also has a mechanism to make a general remark to the advisers: it is the Note which gets also pinned down on the bulletin board. To write it, the negotiator must select the typewriter icon on the top of the bulletin board and gets a window resembling a message window.

Comments can be placed by the advisers on any item of the bulletin board. They simply select the item on the bulletin board and then select the Comment button. At this point, they are allowed to write a comment which is afterwards concatenated with other previous 
comments. These comments can be viewed by choosing the Comment icon in the respective bulletin board item window.

Face votes can also be placed over requests, evaluations, notes and agreements. A user drags one of the faces shown on the lower part of the control panel and drops it over the desired item. The system will place the person's name under the face on the control zone of the item.

Any comment or vote appearing on bulletin board items are signaled in their closed (pinned down) format. For example, in Fig. 2 the closed Request has votes and comments.

\section{HISTORY MANAGEMENT}

As it was mentioned, Share sessions can be reviewed afterwards. Read messages are not automatically deleted by the system and thus they can be reviewed as well.

The $\log$ feature in the control panel displays - when selected - a listing of all SHINE interactions of the negotiating team including the time of occurrence.

\section{IMPLEMENTATION}

A prototype of the system was developed using networked Sun Sparc workstations running SunOs 4.1.2 and OpenWindows 3.0. Internal communication was implemented with RPC (Bloomer (1991)), which uses a client-server architecture. Messages from all users are transmitted via one "message router", which is a software process running in a machine. Messages from the user programs to the message router are sent using the asynchronous ONC RPC technique. Messages from the router to the user programs use a simplified asynchronous Follow-up RPC strategy (Bloomer (1991)). This approach allows the router to handle communication errors, avoiding unwanted messages blocking. Another function of the router is to enforce the permitted communication links: among negotiators or among team members only. Finally, the router guarantees the correct sequence of messages through the network.

The interface has been written using Guide 3.0 (Sun Microsystems (1991)) and rpcgen (Sun Microsystems (1988)). The programming language was standard C.

The objective of this prototype is to show the capabilities of the system and let some people involved in real negotiations try it. The prototype accepts up to 72 users, but it has been tested only up to 12 . Each user requires more than $3 \mathrm{MB}$ of core. Another restriction of this implementation is that all users must sign on at the beginning of the negotiating session in order to maintain data consistency. This prototype has no built-in tight security measures which a system applicable to real negotiations should have. Lastly, the approach taken to issues such as performance, reliability and data management is simple and not appropriate for a final software product. 


\section{CONCLUSIONS}

The design of a collaborative multimedia system to assist large-scale negotiation has been described. A prototype implementation has been tested but it has not been used in real negotiations yet.

SHINE provides multi-channel communication features between a negotiator and his individual assistants, between a negotiator and the group of advisers, and among negotiators. This communication can occur while a negotiation session is in progress. The system is not bound to any bargaining strategy or model and thus, a negotiating team may choose a suitable tactical approach at will.

The divergent tasks (as defined by Nunamaker et al. (1991)) of sending messages, making evaluations, doing brainstorming and writing comments are supported by the system. The hard problem of reaching consensus in distributed environments (Chen et al. (1994)) has been circumvented by seating people who need to do convergent tasks in a face-to-face environment.

The advisers are provided with enough privacy to have their discussions, removing in this way a physical restriction of computerless negotiations. The negotiators get tools to communicate ideas efficiently through the electronic board. The system implements these functions through an intuitive, quick-to-use interface.

Simplicity of use is one of the main design objectives and perhaps many negotiators may get used to the system. In the worst case, at the beginning, one assistant may sit beside the negotiator and handle the workstation, showing him all interesting input the other assistants may provide him. In the long run, even the most technology-opposed negotiators may feel attracted to ask for services from his collaborators through the workstation.

It is not clear the usefulness of the video-voice messages. It may become valuable in some cases and not in others. Other tools may be ignored by a negotiating team: they may not use agreements and notes at all, and decide to use telegrams only for very important messages, for example. In this same flexibility of tools vein, the Definitions feature makes possible adaption to different preferences and cases.

\section{ACKNOWLEDGEMENT}

Alejandra Gálvez helped in the production of drawings used in this paper. Our appreciation to two anonymous referees whose comments helped to improve a draft of the paper.

\section{REFERENCES}

Bacharach, S., and Lawler, E. (1981) Bargaining: Power, Tactics and Outcomes. JosseyBass, San Francisco, CA

Bettinghaus, E. (1980) Persuasive Communication, Holt, Rinehart and Winston, New York, NY, 2nd. Ed.

Bloomer, J (1991) Power Programming With RPC. O'Reilly \& Associates, Inc. Sebastopol, CA. 
Bly, S., Minneman, S.(1990) Commune: A Shared Drawing Surface. ACM Conf. on Office Information Systems, (April), Cambridge, MA, pp 184-192.

Chen, H., Hsu, P., Orwig, R., Hoopes, L. and Nunamaker, J.F.(1994) Automatic Concept Classification of Text From Electronic Meetings. Communications of the ACM, Vol. 37, No. 10, pp56-73.

Ellis, C.A., Gibbs, S.J. and Rein, G.L.(1991) Groupware: Some Issues and Experiences. Communications of the ACM. Vol. 34 No. 1, pp39-58.

Fish, R., Kraut, R., Leland, M. (1988) Quilt: A Collaborative Tool For Cooperative Writing, SIGOIS Bulletin, Vol. 9 Nos. 2 \& 3, pp30-37.

Fisher, R. and Ury, W.(1981) Getting To Yes. Houghton-Mifflin. Boston, MA.

Fraser, N. M., and K. W. Hipel (1984) Conflict Analysis: Models and Resolutions. North-Holland. New York, NY.

Freund, Julien (1983) Sociologie du Conflict. Presses Universitaires de France. Paris, France. (in French).

Fuller, D., Mujica, S., Pino, J. A.(1993) The Design of an Object-Oriented Collaborative Spreadsheet With Version Control and History Management, ACM Symposium on Applied Computing (SAC 93), Indianapolis, ILL (February), pp416-423.

Hahn, U., Jarke, M. and Rose, T.(1991) Teamwork Support in a Knowledge-Based Information Systems Environment. IEEE Trans. on Soft. Eng,. 17(5), pp. 467-482.

Karbe, B., Ramsperger, N., Weiss, P.(1990) Support of Cooperative Work by Electronic Circulation Folders. ACM Conf. on Office Information Systems (April), Cambridge, MA, pp109-117.

Malone, T.W. and Crowston, K.(1990) What is Coordination Theory and How Can it Help Design Cooperative Work Systems. In Halasz, F. (ed): CSCW 90: Proceedings of the Conference on Computer-Supported Cooperative Work. Los Angeles, CA (Oct.), pp357-370.

Nierenberg, G.I. (1973) Fundamentals of Negotiating. Hawthorn Books. New York, NY).

Nunamaker, J.F., Vogel, D., Heminger, A. and Martz, B.(1989) Experiences At IBM With Group Support Systems: A Field Study. Decision Support Systems, Vol. 5, pp 183196.

Nunamaker, J.F., Dennis, A., Valacich, J.S., Vogel, D. and George, J.F.(1991) Electronic Meeting Systems to Support Group Work. Communications of the ACM, Vol. 34, No. 7 , pp40-61.

Pino, J. A., Fabres, E.(1993) Design of the User Interface of a Collaborative Text Writing System, 5th. Int. Conf. on Human-Computer Interaction (HCI 93), Orlando, FL (Aug.) In: Salvendy, G. and M.J. Smith (eds.): Human-Computer Interaction Software and Hardware Interfaces", Elsevier, Amsterdam, pp. 50-55.

Schmitt, Carl (1985) Der Huter der Verfassung. 3. Aufl. Duncker \& Humblot. Berlin, Germany. (in German).

Sheridan, T. (1971) Technology for Group Dialogue and Social Choice, AFIPS Fall Joint Computer Conference (Nov.), Las Vegas, Nev., AFIPS Press, Reston, VA, pp327-335.

Stefik, M., Foster, G., Bobrow, D., Kahn, K., Lanning, S., Suchman, L.(1987) Beyond the Chalkboard: Computer Support for Collaboration and Problem Solving in Meetings,

Communications. of the ACM, Vol. 30, No. 1 (Jan.), pp32-47.

Sun Microsystems, Inc.(1991) Open Windows Developer's Guide 3.0 - User's Guide.

Mountain View, CA.

Sun Microsystems, Inc.(1988) Network Programming. Mountain View, CA. 